\title{
Undercooled and underused: 3D crystal morphology as a petrologic indicator
}

MARTIN F MANGLER, MADELEINE C S HUMPHREYS, ALEXANDER A IVESON AND FABIAN B WADSWORTH

Durham University

Presenting Author: martin.mangler@durham.ac.uk

Crystal morphologies in igneous rocks reflect the magmatic conditions effective during their formation. It is widely known that the degree of undercooling controls crystal shape, varying from equant morphologies at low undercooling to acicular, skeletal and dendritic diffusion-limited growth forms at high undercooling. However, this relationship has not been systematically quantified for variable magma compositions, and underlying growth mechanisms are not fully understood, particularly at intermediate to low undercooling. Difficulties in reconstructing 3D shapes from 2D textural data add further complexity. As a result, 3D crystal shape is rarely used as independent evidence in textural studies despite its diagnostic potential, and instead, is used (if at all) to refine crystal size distribution measurements, where usually a single shape descriptor is assumed for the entire crystal population. We suggest that, given its crucial role in controlling the packing density and mechanical properties of crystal mushes, as well as rheological properties of ascending magmas, the variation of $3 \mathrm{D}$ crystal shape should be a key component of petrologic models.

A compilation of 3D plagioclase morphologies in natural rocks and experiments shows large variations as a function of undercooling, crystal size and magma composition. Plagioclase phenocrysts show broadly tabular 3D shapes (short:intermediate:long axis $\sim 1: 2: 3$ ) indicative of overall low undercooling during their crystallisation, consistent with low cooling rates in magmatic reservoirs at high $\mathrm{pH}_{2} \mathrm{O}$. In contrast, 3D shapes of microlites are prismatic in rhyolites but thin tablets in basaltic melts, and they both approach more equant shapes at lower undercooling. These data suggest that in addition to the primary effective undercooling (expressed through temperature or $p \mathrm{H}_{2} \mathrm{O}$ ), crystal shapes are also affected by kinetics and the physicochemical properties of the host magmas through their influence on interfacial energy and growth mechanism. The patterns revealed by this literature compilation caution against the use of a single shape descriptor to analyse crystal size distributions. More importantly, experimental mapping of 3D crystal shape evolution as a function of undercooling may allow for crystal morphologies to be used as robust indicators of magmatic processes and timescales, both at high and low pressures. 